
cancer, and type 2 diabetes and improves mental health. Findings are suggestive that endurance-type physical activity may reduce the risk of developing obesity, osteoporosis, and depression and may improve psychological well-being and quality of life. There is promising evidence that muscle strengthening (resistance) exercise reduces the risk of falling and fractures among the elderly (Surgeon General, 1996)."

- 2001: The consensus statement from the Dose-Response Issues Concerning Physical Health: An Evidence-based Symposium stated: "Regular physical activity is associated with a reduction in all-cause mortality, fatal and nonfatal total cardiovascular disease, and coronary heart disease. It is also associated with a reduction in the incidence of obesity and type 2 diabetes mellitus, and improvement in the metabolic control of individuals with established type 2 diabetes. Furthermore, physical activity is associated with a reduction in the incidence of colon cancer and osteoporosis. Further benefits of regular physical activity include improved physical function and independent living in the elderly. Individuals with high levels of physical activity are less likely than those with lower levels to develop depressive illness." (Kesaniemi et al., 2001). Thus, it is clear from multiple consensus statements that sedentary lifestyle increases the risk of chronic health conditions. A comprehensive listing of those health conditions whose risk is increased by sedentary living is given in Table 1 .

Therefore, given these facts, we have coined the phrase: Sedentary Death Syndrome (SeDS) to categorize the emerging entity of sedentary lifestyle-mediated disorders that ultimately result in increased mortality. We believe this term is appropriate to describe the nature of the war we are fighting, considering that the word "syndrome" is from the Greek word "syndromē," which means "running together." Currently, a syndrome is defined as "a group of symptoms that together are characteristic of a specific disorder, disease, or the like" (Random House, 1997), where disease is defined as an interruption, cessation, or disorder of body function, system, or organ (Stedman's, 2000). Weak skeletal muscles, low bone density, hyperglycemia, glucosuria, low serum HDL, obesity, low physical endurance, and resting tachycardia are a set or group of symptoms that together characterize SeDS.

\section{Casualties of war}

Before embarking on delineating the toll modern chronic diseases inflict upon our citizens, it is necessary to define what is meant by "chronic disease. This is a condition that is slow in its progress and long in its continuance (Dorland's, 1974). In contrast, "acute disease is a condition characterized by a swift onset and short course" (Dorland's, 1974). Thus, the incubation period for a chronic disease, such as type 2 diabetes, is years and is generally incurable, while an acute disease, such as a common cold, has an

\begin{tabular}{|l|l|}
\hline \multicolumn{2}{|c|}{$\begin{array}{c}\text { Table 1: Conditions that are caused or } \\
\text { worsened by sedentary lifestyle. }\end{array}$} \\
\hline $\begin{array}{l}\text { Sedentary living increases } \\
\text { these conditions. }\end{array}$ & $\begin{array}{l}\text { Sedentary living increases the } \\
\text { progression of these conditions. }\end{array}$ \\
\hline Angina, heart attack, coronary & Chemotherapy \\
artery disease & Chronic back pain \\
Breast cancer & Debilitating illness \\
Colon cancer & Disease cachexia \\
Congestive heart failure & Falls resulting in broken hips \\
Depression & Physical frailty \\
Gallstone disease & Spinal cord injury \\
High blood triglyceride & Stroke \\
High blood cholesterol & Vertebral/femoral fractures \\
Hypertension & \\
Less cognitive function & \\
Low blood HDL & \\
Lower quality of life & \\
Obesity (more difficult time & \\
with weight control) & \\
Osteoporosis & \\
Pancreatic cancer & \\
Peripheral vascular disease & \\
Physical frailty & \\
Premature mortality & \\
Prostate cancer & \\
Sleep apnea & \\
Stiff joints & \\
Stroke & \\
Type 2 diabetes & \\
\end{tabular}

incubation period of merely days and its clinical course is usually completed within weeks. Chronic health condition is a general term that includes both chronic diseases and impairments (Hoffman, Rice, and Sung, 1996).

\section{Casualties for all chronic health conditions combined.}

Approximately 90 million US inhabitants had one or more chronic health conditions in 1987 (88.5 million of those were in non-institutionalized settings and 1.5 million people lived in nursing or personal care homes) (Hoffman, Rice, \& Sung, 1996). About 32.2 million of these people had activity limitations associated with their chronic health conditions (Hoffman, Rice, \& Sung, 1996). Of these, 9.2 million were unable to perform their major activity, as appropriate for their age. Rates of chronic conditions varied with age and were highest among the elderly, with frequencies of having at least one chronic condition being: $88 \%$ in elderly ( $>65$ years), $68 \%$ in 45 -64-year-olds, $35 \%$ in 18 -44-year-olds, and $25 \%$ in 18 years and younger. However, due to the absolute size of each of these age groups, adults 18 to 64 years old accounted for $60 \%$ of all non-institutionalized persons with chronic conditions.

Another category of chronic condition is often referred to as comorbidity. The term comorbidity is defined as "a concomitant but unrelated pathologic or disease process, usually used in epidemiology to indicate the coexistence of two or more disease processes" (Stedman's, 2000). One in six children with chronic conditions (17\%) had a 
comorbidity (Hoffman, Rice, \& Sung, 1996). Compared with those with only one chronic condition, these children were more likely to be limited in their activity, experienced more days spent in bed, and had more absences from school (Hoffman, Rice, \& Sung, 1996).

\section{Casualties by specific chronic health conditions.}

Coronary heart disease. Coronary heart disease has been the number one cause of death in the United States in the 20th century for every year but one (1918) (American Heart Association, 1998). Cardiovascular disease was the primary cause of 949,619 deaths (41\% of all deaths) in 1998 and was the primary or contributing cause of 1.4 million deaths $(60 \%$ of all deaths) (American Heart Association, 2000).

Cardiovascular disease claims more lives each year than the next seven prevalent causes of death combined (American Heart Association, 1998). The American Heart Association stated that the number of people dying from diseases of the heart has risen by $37 \%$ (200,000 additional yearly deaths) from 1950 to 1996 (American Heart Association, 1998), while the total US population increased by $43 \%$. Although annual death rates from cardiovascular disease have just recently begun to decline ( $21.3 \%$ from 1986 to 1996), the absolute number of cardiovascular deaths declined only $2 \%$ in the same 10-year period (American Heart Association, 1998).

Type 2 diabetes. The increase in type 2 diabetes is being called an epidemic (Mokdad et al., 2001). The CDC concluded: "Interventions are needed to improve physical activity and diet in communities nationwide" (Mokdad et al., 2001). A five-fold increase in prevalence of Type 2 diabetes occurred between 1958 and 1993 (Harris \& Eastman, 2000). According to the American Diabetes Association, more than 400,000 people with diabetes die each year, half of them just because of diabetes (American Diabetes Association, 2001). This number is sure to rise for the following reasons. Older textbooks of internal medicine consider type 2 diabetes as a disease rarely seen under the age of 40 years. Recently, Pinhas-Hamiel et al. (1996) noted a 10-fold increase in type 2 diabetes between 1982 and 1994 in adolescents in one Cincinnati hospital. Thus the overall increase in type 2 diabetes is not solely a result of the fact that the mean age of the US population is now growing older (Libman \& Arslanian, 1999). The consequences of this demographic switch are not good. Onset of type 2 diabetes at an early age makes these individuals susceptible to developing diabetesassociated comorbidities such as blindness, end-stage renal disease, amputations, heart disease, and strokes much earlier in life. A recent publication predicts that the number of Americans with diagnosed diabetes is projected to increase $165 \%$, from 11 million in 2000 (prevalence of $4.0 \%$ ) to 29 million in 2050 (prevalence of 7.2\%) (Boyle et al., 2001). The largest percent increase in diagnosed diabetes will be among those aged 75 years $(+271 \%$ in women and $+437 \%$ in men). Type 2 diabetes is also more prevalent in specific ethnicities. The fastest growing ethnic group with diagnosed diabetes is expected to be black males $(+363 \%$ from 2000 -
2050), with black females ( $+217 \%)$, white males $(+148 \%)$, and white females $(+107 \%)$ (Boyle et al., 2001). Of the projected 18 million increase in the number of cases of diabetes in $2050,37 \%$ are due to changes in demographic composition, $27 \%$ are due to population growth, and $36 \%$ are due to increasing prevalence rates (Boyle et al., 2001). The need to administer medical treatment because of these projected increases will likely increase the economic strain on their families and society.

Obesity. The current trend in obesity statistics has also become epidemic (Mokdad et al., 2001). Obesity was estimated to annually account for 280,000-325,000 deaths in the US using 1991 statistics (Allison et al., 1999), and this number is likely growing. The CDC documented the prevalence of obesity in 2000 as being $19.8 \%$ among US adults, reflecting a $61 \%$ increase since 1991 (Mokdad et al., $2001)$. In the year 2000 , a total of 38.8 million US adults were obese (19.6 million men and 19.2 million women), and approximately $2.1 \%$ ( $1.5 \%$ of men and $2.8 \%$ of women) of all participants had morbid obesity (BMI $\geq 40 \mathrm{~kg} / \mathrm{m}^{2}$ ), compared with $0.9 \%$ in 1991 (Mokdad et al., 2001). Also, the percentage of overweight adults (BMI $\left.\geq 25 \mathrm{~kg} / \mathrm{m}^{2}\right)$ increased to $56.4 \%$ in 2000 , compared with $45 \%$ in 1991 (Mokdad et al., 2001). Indeed, the average rate of rise in obesity in the last 10 years accelerated to $6.1 \%$ per year, compared to a $2.2 \%$ per year increase that was noted in the 1960-1994 period (Flegal, et al., 1998).

Like adults, the number of overweight children and adolescents in the US also increased between the 1960-1962 period and the 1988-1994 period, with this rate of increase also accelerating in the final 10-12 years of this interval (Flegal et al., 1998). Approximately 11\% of US children and adolescents were reportedly overweight in the 1988-1994 period (Troiano \& Flegal, 1998). Moreover, the $90 \%$ increase in proportion of obese persons in the 18- to 29-year-old age group from 1991 (with a $7.1 \%$ prevalence of obesity) to 2000 (with a 13.5\% prevalence) (Mokdad et al., 1999; Mokdad, 2001) indicates that those statistics in children are now translating into similar trends within the young adult population of the US. The obesity epidemic is therefore like the type 2 diabetes epidemic in that its advance is not just a sole function of more individuals reaching middle age in the US population. Rather, these statistics indicate that for many individuals these are problems originating in the lifestyles of children and adolescents. Children now exhibit some risk factors for chronic health conditions. Sixty percent of overweight 5- to 10-year-old children already have one biochemical or clinical cardiovascular risk factor, such as hyperlipidemia, elevated blood pressure, or increased insulin levels, and 25\% have 2 or more (Koplan \& Dietz, 1999).

Obesity-related disorders. Obesity is a comorbidity of some of the most prevalent diseases of modern civilization (Jung, 1997; Must et al., 1999). The prevalence of comorbidities rises with increasing body mass index (BMI) (Must et al., 1999). For example, BMI's $>35 \mathrm{~kg} / \mathrm{m}^{2}$ are associated with a 93-fold and 42-fold increased risk of Type 2 diabetes in 
women and men, respectively. The risk of coronary heart disease is increased $86 \%$ by a $20 \%$ rise in body weight in men, whereas this risk is increased 3.6-fold in obese women (Jung, 1997). A higher prevalence of diseases such as hypertension, osteoarthritis, and gallbladder disease is also associated with increasing obesity (Must et al., 1999).

Aging population. The average age of the US population is getting older. Currently, 3.5 million US citizens are 85 years or older. This number will increase as there will be a substantial increase in the relative size of the elderly population after the year 2011 when the oldest members of the baby-boom cohort (people born in 1946) reach the age of 65 . The Census Bureau projects that, by the year 2040, there will be at least 8-13 million Americans 85 years of age or older (Campion, 1994). A quarter of all women and $15 \%$ of all men aged 84 years or older lived in nursing homes in the 1990s (Campion, 1994). Most chronic diseases are also considered age-related diseases, since they clinically manifest themselves to a greater degree later in life (Must et al., 1999). Thus, it is logical to expect the prevalence of modern chronic disorders to rise in future years due to: 1 ) the progressive aging of the US population and 2) the increasing prevalence of chronic disorders noted in younger age groups. Our health care system is headed for trouble unless we soon find a way to implement better preventive measures against the progression of chronic diseases.

\section{Costs of sedentary living}

"Cost" is defined as the "the price paid to acquire, produce, accomplish, or maintain anything" (Random House, 1997). In this review, we will consider "cost" as both money and the non-money effort required to acquire, produce, accomplish, and maintain quality of life, well-being, and health.

\section{Economic costs:}

For all chronic health conditions: Chronic health conditions compose the major health cost according to the following data from Hoffman et al. (1996). While 46\% of people reported chronic conditions in 1987, they accounted for $76 \%$ of the direct medical care costs in the United States. The direct costs of health services and supplies for noninstitutionalized people with chronic conditions totaled $\$ 272.2$ billion in 1987. Annual health care costs for people with chronic conditions, which included care for both their chronic condition and any acute health problems they may have experienced, averaged \$3074 in 1987 compared with $\$ 817$ for persons with only acute conditions. People with more than one chronic condition spent $\$ 4672$ per year on health care in 1987 compared with $\$ 1829$ for people with only one chronic condition. The indirect costs of chronic health conditions are also staggering. The loss to the economy amounted to $\$ 161.3$ billion or an average of $\$ 98,304$ per death. Mortality costs combined with morbidity costs amounted to $\$ 234$ billion in total indirect costs due to chronic conditions in 1990.

In addition, individuals with chronic health conditions accounted for disproportionately large utilization, and hence, cost of health care resources, both in services and supplies. Almost $96 \%$ of home care visits, $83 \%$ of prescription drug use, $66 \%$ of physician visits, and $55 \%$ of emergency department visits were made by people with chronic health conditions, and they represented $69 \%$ of hospital admissions, requiring longer hospital stays ( 7.8 days), compared to persons without chronic health conditions (4.3 days) (Hoffman, Rice, \& Sung, 1996). It would be logical to target the largest health care expense if attempts are made to reduce health care costs.

For sedentary disorders: The direct and indirect costs of sedentary lifestyle to chronic health conditions were reported to be in excess of $\$ 150$ billion (cost in 2000 dollars for 1987 incidences) (Pratt, Macera \& Wang, 2000). As health care costs are $\$ 1.3$ trillion/year in the US, a rough approximation is that physical inactivity accounts for approximately $15 \%$ of the US health care budget. A simple calculation confirms this report. The costs of cardiovascular disease ( $\$ 298.2$ billion in the year 2001; American Heart Association) and type 2 diabetes ( $\$ 98$ billion, American Diabetes Association) combine to $\$ 396$ billion/year. A 30\% reduction in these two disorders would save the US economy $\$ 119$ billion. Such a reduction is feasible because a $30 \%$ reduction in the occurrence of coronary artery disease, stroke, and type 2 diabetes was achieved in those who undertook a minimum of 2.5 hours of brisk walking per week as compared to the sedentary group, based on the results of the large population nurses' health studies (Hu et al., 1999; Hu et al., 2000; Manson et al., 1999). Costs for inactivity in other disorders are being reported. The proportion of direct medical costs associated with physical inactivity in inactive US adults with arthritis was $\$ 1,250 /$ patient, which is about $12.4 \%$ of direct costs, or about $\$ 8$ billion/year (Wang et al., 2001).

\section{Mortality costs:}

Seven out of 10 deaths (1.6 million out of 2.3 million) in the US in 1996 were due to four chronic health conditions (total cardiovascular diseases, all cancers, chronic obstructive pulmonary disease, and diabetes). These 1.6 million deaths represented 24.3 million years lost, with an average of 14.8 years per death (Hoffman, Rice, \& Sung, 1996). About 15\% of the 1.6 million chronic health conditions were due to sedentary lifestyle alone.

Hahn et al. (1990) reported that 256,686 deaths in the USA were attributed to being either sedentary or irregularly physically active in $1986(205,254$ from coronary heart disease; 43,063 from stroke, and 8,369 from colon cancer; the effect of physical inactivity on other chronic conditions such as type 2 diabetes was not determined). The following information was used to confirm the 250,000 premature deaths from physical inactivity. A consensus statement read: “. . physical activity expending $1000 \mathrm{kcal} / \mathrm{wk}(4200 \mathrm{~kJ} / \mathrm{wk})$ is associated with as much as a $30 \%$ reduction in all-cause mortality rates" (Kesaniemi et al., 2001). As there are approximately 706,000 deaths in the USA each year from coronary heart disease (459,841 deaths; American Heart 
Association); type 2 diabetes (198,140 deaths; American Diabetes Association), and colon cancer (48,100 deaths; American Cancer Society) (see respective society web pages for sources) then $30 \%$ of the deaths for coronary heart disease, type 2 diabetes, and colon cancer (or 212,000 deaths) would be prevented by moderate-intensity physical activity that expended $1000 \mathrm{kcal} / \mathrm{wk}$. The number of deaths from sedentary living is two times greater than that from microbial agents and also exceeds all deaths from firearms, illicit usage of drugs, sexually transmitted diseases, and motor vehicle accidents (McGinnis \& Foege, 1993). Thus, a major cause of death in the US is sedentary living. In other words, the sedentary death syndrome (SeDS) comprises one of the top three causes of all-cause mortality in the US today, and directly contributes to the current second highest death rate in the country, which is obesity. Therefore, in the last 100 years, the leading causes of death have dramatically shifted from the scourges of infectious disease (in 1900), to tobacco, obesity, and SeDS (in 2000), which in essence constitute the new scourge for humanity. This is why the war against modern chronic diseases needs to be waged.

\section{Are we winning the war against chronic health conditions?}

Sadly, the answer is a resounding "No!" There has been a dramatic increase in the incidence of chronic health conditions in the latter part of the 20th century. Concurrent with this increase has been a reduction in the physical activity needed for daily sustenance. It is indeed a great irony that the disease consequences of physical inactivity, itself, are a negative by-product of the modern laborsaving devices that reduced the amount of physical activity needed to obtain the essentials for daily living and so free time to allow for the tremendous progress of the latter part of the 20th century.

\section{Fighting the full battle: being proactive, instead of reactive}

No one would deny that physicians and biomedical scientists have increased our understanding of the underlying pathophysiologic and therapeutic mechanisms of chronic disease at an impressive rate. From such phenomenal progress it is only natural for one to expect that medical research will cure all diseases and consequently, believe that it would be unnecessary to indulge in the practice of lifestyle behavior modification that would lower the incidence risk of such chronic maladies. Thus, the majority of our population must not be convinced enough that 30 minutes of moderate physical activity (e.g., brisk walking) each day is vital because of the entrenched belief that modern medicine will cure all ills. However, most biomedical advances for the treatment of chronic diseases are being concentrated after the disease is clinically observed and diagnosed. At best, such treatments stabilize the health condition, preventing further progression. As a rule, these treatments do not restore normal pre-disease function and health.
Therefore, we believe that a better therapeutic strategy would be to prevent pathology from ever occurring in the first place by maintaining physiologic homeostasis, and thereby limiting the progression of overt clinical disease. Research to cure diseases is definitely indispensable and should indeed be continued. However, a new emphasis on prevention should be recognized, now more than ever, especially in light of the burgeoning and powerful clinical epidemiological data.

Recently, it was shown that $82 \%$ of coronary heart disease (Stampfer, et al., 2000) and 91\% of type 2 diabetes (Hu et al., 2001) is caused by high-risk lifestyles. Thus, the corollary by logical inference is that a large majority of such diseases are preventable by engaging in low-risk lifestyles. Low-risk behavior was defined as a combination of five variables: BMI of less than 25; a diet high in cereal fiber and polyunsaturated fat and low in trans fat and glycemic load (which reflects the effect of diet on the blood glucose level); engagement in moderate-to-vigorous physical activity for at least half an hour per day; no current smoking; and the consumption of an average of at least half a drink of an alcoholic beverage per day (Hu et al., 2001). Thus, physical activity forms a vital component of our defense arsenal in the prevention of coronary heart disease and type 2 diabetes. Hence, we propose that the fight against chronic health conditions can be made more effective by expanding our biomedical research efforts into the little explored (and even less supported) battlefield of primary prevention by being proactive.

\section{Flushing out the silent enemy: primary prevention of chronic health conditions.}

As we emphasized in a previous review (Booth et al., 2000), the treatment of the symptoms and not the cause, or to treat the cause after it precipitates the clinically overt disease, may not be the wisest strategy as it will cost more money, lower the quality of life, and accentuate human suffering. Conversely, primary prevention is unusual as a "medicine" in that it is implemented before a chronic health condition is clinically manifested. That is, a chronic health condition may never reach its pathologic threshold to compromise the health of an individual if it is attacked at its origin to delay and/or prevent its progression. Preventing a chronic health condition in the first place is more humane and produces less suffering than secondary or tertiary treatment of full-blown overt disease. In other words, the practice of primary prevention is a fundamental demonstration of the very essence of the Hippocratic oath: "first, do no harm." It is indeed ironic that practicing primary prevention is considered basic common sense in other inanimate aspects of our daily life, when we neglect to do the same when it comes to our own personal health, a most fragile entity. For example, is it not less damaging and expensive for an automobile to undergo routine maintenance such as oil changes rather than to undergo a complete engine replacement after several years of neglect? Moreover, 
primary prevention has even been used successfully against acute diseases. Smallpox, polio, and other infectious diseases have been virtually eliminated through the use of primary prevention methods (i.e., vaccination). If primary prevention has been successfully employed in the war against these other diseases, why not use this strategy against modern chronic disease?

\section{Weapons to combat sedentary-induced diseases}

The weapon of a strong case against inactivity-related disorders: Cost can be used as a weapon to fight for a change to a more physically active society. For example, Colditz (1999) suggested that focused strategies to increase the level of physical activity will likely produce substantial benefits through reduced health care costs as well as through reduction in indirect costs and gains in quality of life. One crucial target for potential reductions in health care cost would be to eliminate physical inactivity by replacing it with moderate-intensity activity for the $70 \%$ of the US population who now are at high risk for SeDS. However, this weapon has not been widely employed. Fries et al. (1993) wrote: "Advocates of health promotion have themselves caused delays, first by not making cost reduction a primary goal, and second by neglecting rigorous economic evaluation." It is our belief that there now exists sufficient and rather convincing cost-of-illness data (a minimum of $\$ 150$ billion in the annual direct and indirect costs for physical inactivity, Pratt, Macera \& Wang, 2000) to demand immediate cost effectiveness studies to rationally justify the promotion of moderateintensity physical activity to reduce health care expenditures. We believe that this is a weapon to force policies for the reinsertion of physical activity into daily life in order to lessen the unnecessary human suffering from chronic health conditions.

The weapon of activism and advocacy: Professionals associated with physical activity in their occupations must become greater advocates to facilitate the incorporation of physical activity as a part of daily living. A few examples that can be initiated in specific age groups include:

- Children and adolescents: Promotion of $60 \mathrm{~min}$ of daily physical activity by: 1) school recesses, 2) lifetime physical activity in physical education classes, 3) teaching in schools of the biological and medical basis by which physical inactivity increases the risk of chronic health conditions, 4) training students how to count calories from walking and climbing stairs, 5) teaching and encouraging healthy nutrition habits by minimizing junk foods in school cafeterias, 6) recreational sports for those students whose skills do not allow them to compete on interscholastic athletic teams, and 7) encourage children and youth to engage in 60 minutes of physical activity daily for six weeks to qualify for the Presidential Active Lifestyle Award (PCPFS, 2001). Communities should be made to be friendly and safe for children to be physically active by providing safe paths to walk or cycle to school, and by the opening of school gyms for after-hours physical activities.

- Adults: Family play and outings should be promoted by providing neighborhood sidewalks, safe parks in urban areas, school gyms, and community recreational buildings. Adults should be encouraged to undertake a minimum of 30 minutes of physical activity each day by their employers, as part of their "health coverage benefits." Legislators, corporate heads, and community leaders should be lobbied to support a physically active America.

- Seniors: Promotion of a physically active lifestyle should occur through the inclusion of physical activity at social gatherings. Seniors should be allowed free access to strength training equipment, recreational facilities, and educated on the consequences of a sedentary lifestyle on their vitality, quality of life, and ability to perform the tasks of daily living.

In a similar vein, another class of weapons is dissemination of information to the general public via various formats and media. Providing greater awareness and educating the general public about the existence of the large body of scientific evidence supporting the many positive benefits of a physically active lifestyle in promoting good health (Chakravarthy, Joyner, and Booth, 2002) not only broadens our understanding of the underlying problem, but it also empowers us to become proactive in our own ways to lead a healthier lifestyle. Such active individual involvement would indeed be a potent weapon to bring about a fundamental shift in our thinking as we begin to redirect our focus towards winning the ongoing war on modern chronic diseases.

\author{
Address correspondence to: \\ Frank W. Booth, Ph.D. \\ Professor, Biomedical Sciences \\ Department of Biomedical Sciences \\ 1600 E. Rollins Street, E102, Vet. Med. Bldg. \\ Columbia, Missouri 65211, USA \\ Phone: +1 573.882.6652 \\ Fax: +1573.884 .6890$ \\ E-mail: boothf@missouri.edu
}

\section{ACKNOWLEDGMENTS}

This work was written while supported by NIH grant AR19393 (FB). 


\section{How to become a soldier in the war against physical inactivity-induced chronic health conditions}

Each person reading this article is urged to become a foot soldier in his or her own community, advocating the inclusion of appropriate physical activity for health. Many organizations exist to promote physical activity. A foot soldier should advocate that these organizations become more proactive in presenting the facts in this review to those decision makers who in turn can make policies to facilitate a more physically active lifestyle, and thereby play a direct part in facilitating a healthier and more prosperous America. Further information can be obtained from the website http://www.endseds.org.

Frank W. Booth, Ph.D., University of Missouri

Manu V. Chakravarthy, M.D., Ph.D., University of Pennsylvania

Please Post

President's Council on Physical Fitness \& Sports

200 Independence Avenue, S.W., Washington, DC 20201

(202) 690-9000 • FAX (202) 690-5211 


\section{References}

Allison, D. B., Fontaine, K. R., Manson, J. E., Stevens, J., \& Vanltallie, T. B. (1999). Annual deaths attributable to obesity in the United States. JAMA 282, 1530-1538

American Diabetes Association. (2001). Diabetes 2001: Vital Statistics. Alexandria, VA: American Diabetes Association.

American Heart Association. (1998). 1999Heart and Stroke Statistical Update. Dallas, TX: American Heart Association.

American Heart Association. (2000). 2001 Heart and Stroke Statistical Update. Dallas, TX: American Heart Association.

Booth, F. W., Gordon, S. E., Carlson, C. J., \& Hamilton, M T. (2000). Waging war on modern chronic diseases: primary prevention through exercise biology. J. Appl. Physiol. 88 774-787.

Boyle, J. P., Honeycutt, A. A., Narayan, K. M, Hoerger, T. J., Geiss, L. S., Chen, H., \& Thompson, T. J. (2001). Projection of Diabetes Burden Through 2050 Impact of changing demography and disease prevalence in the U.S. Diabetes Care 24 1936-1940.

Campion, E. W. The oldest old. (1994). N. Engl. J. Med. 330 1819-1820.

Chakravarthy, M. V., Joyner, M J., and Booth, F. W. An obligation for primary care physicians to prescribe physical activity to sedentary patients to reduce the risk of chronic health conditions. (2002). Mayo Clinic Proc. 77: February issue.

Colditz, G. A. (1999). Economic costs of obesity and inactivity. Med. Sci. Sports Exerc. 31, Suppl S663-S667.

Dorland's Illustrated Medical Dictionary (25th ed.). (1974). Philadelphia, PA: Saunders

Flegal, K. M, Carrol, M D., Kuczmarski, R. J., \& Johnson, C. L. (1998). Overweight and obesity in the United States: prevalence and trends, 1960-1994. Int. J. Obesity 22, 39-47.

Fries, J. F., Koop, C. E., Beadle, C. E., Cooper, P. P., Endland, M J., Greaves, R. F., Sokolov, J. J., Wright, D., \& the Health Project Consortium. (1993). Reducing health care costs by reducing the need and demand for medical services. New Engl. J. Med. 329 321-325.

Hahn, R. A., Teutsch, S. M, Rothenberg, R. B., \& Marks, J. S. (1990), Excess deaths from nine chronic diseases in the United States, 1986 JAMA 264, 2654-2659.

Harris, M I. \& Eastman, R. C. (2000). Early detection of undiagnosed diabetes mellitus: a US perspective. Diabetes Metab. Res. Rev. 16 230-236.

Hoffman, C., Rice, D., \& Sung, H. Y. (1996). Persons with chronic conditions. Their prevalence and costs. JAMA 276 1473-1479.

Hu, F. B., Manson, J. E., Stampfer, M J., Colditz, G., Liu, S., Solomon, C. G., \& Willett, W. C. (2001). Diet, lifestyle, and the risk of type 2 diabetes mellitus in women. N. Engl. J. Med. 345, 790-797.

Hu, F. B., Sigal, R. J., Rich-Edwards, J. W., Coldit, G. A., Solomon, C. G., Willett, W. C., Speizer, F. E., \& Manson, J. E. (1999). Walking compared with vigorous physical activity and risk of type 2 diabetes in women: a prospective study. JAMA 282, 1433-1439.

Hu, F. B., Stampfer, M J., Coldit, G. A., Ascherio, A., Rexrode, K. M, Willett, W. C., \& Manson, J. E. (2000). Physical activity and risk of stroke in women. JAMA 283 2961-2967.

Jung, R. T. (1997). Obesity as a disease. Br. Med. Bull. 53 307-321.

Kesaniemi, Y. K., Danforth, E. Jr., Jensen, M D., Kopelman, P. G., Lefebvre, P., \& Reeder, B. A. (2001). Dose-response issues concerning physical activity and health: an evidence-based symposium. Med. Sci. Sports Exerc. 33(6Suppl), S351-S358.
Koplan, J. P. \& Dietz, W. H. (1999). Caloric imbalance and public health policy. JAMA 282 1579-1581.

Libman, I. \&Arslanian, S. A. (1999). Type 2 diabetes mellitus: no longer just adults. Pediatr. Ann. 28 589-593.

Manson, J. E., Hu, F. B., Rich-Edwards, J. W., Coldit, G. A., Stampfer, M J., Willett, W. C., Speizer, F. E., \& Hennekens, C. H. (1999). A prospective study of walking as compared with vigorous exercise in the prevention of coronary heart disease in women. N. Engl. J. Med. $341,650-658$

McGinnis, J. M \& Foege, W. H. (1993). Actual causes of death in the United States. JAMA 270 2207-2212

Mokdad, A. H., Bowman, B. A., Ford, E. S., Vinicor, F., Marks, J. S., \& Koplan, J. P. (2001). The continuing epidemics of obesity and diabetes in the United States. JAMA 286 1195-1200

Mokdad, A. H., Serdula, M K., Dietz, W. H., Bowman, B. A., Marks, J. S., \& Koplan, J. P. (1999). The spread of the obesity epidemic in the United States, 1991-1998. JAMA 282 1519-1522

Mist, A., Spadano, J., Coakley, E. H., Field, A. E., Coldit, G., \& Dietz, W. H. (1999). The disease burden associated with overweight and obesity. JAMA 282, 1523-1529.

Pate, R. R., Pratt, M, Blair, S. N., Haskell, W. L., Macera, C. A., Bouchard, C., Buchner, D., Ettinger, W., Heath, G. W., King, A. C., et al. (1995). Physical activity and public health. A recommendation from the Centers for Disease Control and Prevention and the American College of Sports Medicine. JAMA 273 402-407.

Pinhas-Hamiel, O., Dolan, L. M, Daniels, S. R., Standiford, D., Khoury, P. R., \& Zeitler, P. (1996). Increased incidence of non-insulin-dependent diabetes mellitus among adolescents. J. Pediatr. 128 608-615.

Pratt, M, Macera, C. A., \& Wang, G. (2000). Higher direct medical costs associated with physical inactivity. The Physician and Sportsmedicine 28 63-70, 2000

President's Council on Physical Fitness and Sports (2001). The President's Challenge Physical Activity and Fitness Awards Program. Washington, DC: PCPFS.

Random House Webster's Unabridged Dictionary, 2nd Ed. Random House: New York, 1997.

Stampfer, M J., Hu, F. B., Manson, J. E., Rimm, E. B., \& Willett, W. C. (2000). Primary prevention of coronary heart disease in women through diet and lifestyle. N. Engl. J. Med. 343 16-22

Stedman's Medical Dictionary, 27th edition (2000). Baltimore: Lippincott Williams \& Wilkins.

Troiano, R. P. \& Flegal, K. M (1998). Overweight children and adolescents: description, epidemiology, and demographics. Pediatrics 101, Suppl.: 497-504.

USDHHS (1996). Surgeon General's report on physical activity and health. (1996). From the Centers for Disease Control and Prevention. Washington, DC: US Government Printing Office.

Wang, G., Helmick, C. G., Macera, C., Zhang, P., \& Pratt, M (2001). Inactivity-associated medical costs among US adults with arthritis. Arthritis Rheum. Arthritis Care Res. 45 439-45. 